\title{
Application of Dynamic Value Stream Mapping in Warehousing Context
}

\author{
Shiva Abdoli ${ }^{1}$, Sami Kara ${ }^{1} \&$ Bernard Kornfeld ${ }^{1}$ \\ ${ }^{1}$ University of New South Wales, School of Mechanical \& Manufacturing Engineering, Australia \\ Correspondence: Shiva Abdoli, University of New South Wales, Sydney, NSW, Australia. E-mail: \\ s.abdoli@student.unsw.edu.au
}

Received: August 15, 2016

Accepted: September 11, $2016 \quad$ Online Published: October 14, 2016

doi:10.5539/mas.v11n1p76

URL: http://dx.doi.org/10.5539/mas.v11n1p76

\begin{abstract}
Uncertainty within supply chains increases the risk of not meeting objectives. Warehouses can absorb some of these uncertainties, by accumulating inventory. This accumulation has led many to consider warehouses as a source of waste in supply chains. Hence, there is limited research that seeks improving intrinsic warehouse efficiency; particularly in the context of Lean concepts and Value Stream Mapping (VSM). Since, warehouses seek to absorb uncertainty in supply chain by holding inventory; this uncertainty absorption may introduce variability to warehousing function itself. Therefore a methodology is required, which can capture the embodied dynamic within warehousing function. This paper reflects Lean concepts and, in particular, VSM to warehousing context and introduces some methods and guidelines to assure the proper application of VSM in what is an uncertain and dynamic system. In this paper, warehousing function is formulated based on some abstract processes which vary on their output status. This formulation facilitates identifying value-adding activities as one of the most substantial steps, yet confusing in application of VSM in warehousing context. The suggested methods enable fundamental statistical/mathematical analysis, which leverage VSM to a more dynamic evaluation tool. Application of the introduced approach will facilitate the decision making process for warehouse systems evaluation and improvement. The resultant methodology is applied to a factual case and this serves to demonstrate its practical application. It is worth mentioning that the findings applications, which can be termed 'dynamic VSM', are not limited to warehouses but can also be applied to any dynamic environment with non-deterministic processes.
\end{abstract}

Keywords: logistics, warehousing, variable process parameters, vale stream mapping

\section{Introduction}

If supply chains are considered as distribution networks, then warehouses represent the main nodes of those networks. Hence, warehouses can exert a substantial leverage on supply chain service quality(Gray, Karmarkar, \& Seidmann, 1992). This crucial role emphasizes the importance of study in the field of warehouse performance evaluation. Since warehouses like other industrial facilities perform series of coupled processes, the evaluation method should also fit this complex structure. Thus, an approach is necessary which can capture the holistic dynamic interaction among processes while also analysis them individually.

There is a close alignment between performance evaluation and improvement and Lean tools and methods. In short, 'Lean' seeks to improve the performance of operations by eliminating waste (Detty \& Yingling, 2000; Hofer, Eroglu, \& Rossiter Hofer, 2012; Liker \& Convis, 2011; Pavnaskar, Gershenson, \& Jambekar, 2003; Womack \& Jones 2003).VSM is one of the better known Lean tools in the implementation of Lean concepts to production and more recently service industries. VSM is useful in the visualization of core value chain processes, which assists managers in identifying opportunities to achieve required objective. This map provides a high level view of the interdependencies and interactions across different processes as resources, products, or information passes each stage of the stream. This comprehensive illustration enables analysis and evaluation of process chain with respect to desired key performance indicators (KPIs). These VSM properties, and also the promising results that have been achieved by VSM implementation in manufacturing industries, make VSM a promising candidate for warehouse performance evaluation, too. Therefore, this research aims to investigate the application of VSM in a warehousing context, as well as the modifications that might be necessary.

\section{Literature Review}


Generally the research in warehousing can be divided to two fields; design and performance evaluation, with the former topic commanding a broader foundation of research. In this context, design refers to physical design, equipment selection, as well as operational design. Evaluation refers the assessment of the performance of existing designs with respect to various key performance metrics. Since this current research focuses on performance evaluation, only the literature in that area is reviewed. However complexity of warehousing systems made researchers, in either topic, to narrow down the scope of research, and study warehouse design or evaluation topics partially, such as individual analysis of layout or operational policies. Interested readers can find design topics in related literatures (Berg \& Zijm, 1999; J. Gu, Goetschalckx, \& McGinnis, 2007; J. X. Gu, Goetschalckx, \& McGinnis, 2010; Rouwenhorst et al., 2000a)

One of the very first studies in warehouse evaluation proposes the application of 'zero-based analysis. This approach suggests to divide resource consumption to three parts; necessary work, losses and cost. The former refers to required resources in ideal case, losses are expressed as a percentage of the necessary work and the later are monetary units. So, 'zero based analysis develops a reference system in the form of utopian loss-free system such that the reference point is only dependent on the product. The main drawback of this approach is inability to evaluate time-based or quality of service parameters. In addition, the scope of mentioned study is limited to the manual processes. Thus, this approach may have shortcomings on its application to those warehousing processes which require multiple resource type (Henrik, Mats, \& Lars, 1994)

As mentioned, this research aims to investigate the application of VSM in warehousing context for the purpose of warehouse evaluation. Hence, the literatures regarding VSM application in warehousing is critically reviewed. There is a large volume of literature concerning Lean and specifically the application of VSM in manufacturing industries and more recently supply chain, but limited and scarce in warehousing(Ben Naylor, Naim, \& Berry, 1999; Bozer, 2012). When VSM is applied to supply chains, warehouses are generally represented as an inventory 'black box'. This approach neglects to reflect any detailed information in regards to warehouse performance. However, in order to have a lean supply chain, warehouses, as one of the main entities in logistic networks, should be lean as well (Jones, Hines \& Rich, 1997) (Bozer, 2012)

In context of applying lean concepts in logistics management, Myerson suggests considering warehouse function as assembly line constituting several activities. Thus, warehouse efficiency can be improved by some general guidelines such as improving tools and equipment availability (Myerson, 2012).

Mustafa introduces a framework to apply Lean concepts in warehouses. The proposed framework is limited to some theoretical guidelines without providing enough details regarding implementation of Lean tools and techniques. Moreover the guidelines are not generic enough without formal representation which makes it hard to apply them in different situations (Mustafa, 2015).

Garcia carried out one of the earliest applications of VSM in warehousing(Frank C. Garcia, 2013). In the mentioned paper, the scope is limited to unit-load warehouses, however a significant proportion of industrial warehouses operate under-unit-load, which actually requires more considerations in VSM application due to changing the unit of operation in warehousing processes. Moreover, some inconsistencies exist in the published VSM, such as different work in progress units among different stages. The importance of unit consistency in evaluation of process chains and how to achieve it in warehousing context is well discussed in section 2 .

In another work, Dotoli advocates analyzing warehouse operations in three steps with different methods (Dotoli, Epicoco, Falagario, Costantino, \& Turchiano, 2015). In first step, the Unified Modelling Language (UML) is used to describe the warehouse logistics. Then in the next step, VSM is applied to identify non value-adding tasks. In the final step, a mathematical formulation assists on ranking all identified types of wastes which were termed in that paper anomaly. The paper more focuses on ranking anomalies and hence it does not map KPI values as a basis for comparison. Additionally, the research scope is limited to production warehouses, and other types of warehouses are shown as work-in-progress (WIP) boxes without including detailed information about their operational performance.

Bozer attempted to analysis the reflection of some lean concepts in warehousing after investigating lean application in couple of case studies(Bozer, 2012). However the analysis and discussion of value-adding and non-value-adding activities, in the mentioned report, is one of the most important works in this area, but it is not easy to generalize some of the concluded results to all warehouse types. For example, Bozer defines any increment of inventory above a determined minimum level, as warehouse inefficiency. If the study scope is narrowed down to the warehouse, and not whole supply chain, this argument cannot be true for warehouses which their inbound and outbound activities are dictated from the supply chain. Consider, if customer order reduces considerably after receiving new supply consignment, inventory level will exceed the determined 
minimum level. On the other hand, consider if the demand increases and consequently inventory level in warehouse decreases. This reduction does not reflect any improvement in warehouse efficiency. Hence, if supplier or customer changes their behavioral pattern, which lead to increment in inventory level, this is not warehouse inefficiency, but can be inefficiency in supply chain planning or poor demand forecasting. Although the mentioned report puts forward a useful theoretical framework, it does not propose guidelines to utilize Lean concept with application of VSM in warehousing. Due to the complexity of warehouse operations, the paper suggested that processes should be evaluated individually. Moreover, in the mentioned report suggested considering value adding activities, as which, they help to achieve the objectives of the next process. This approach contradicts with Lean concept, because with this approach, any type of waste, inventory or extra transportation can be considered as value adding activity because they support the next process.

Reviewing the current literature shows the critical lack of an integrated approach for warehouse evaluation. Most of the current literature and practices are ad-hoc or not generic enough to be applicable to a broad range of different cases (Gagliardi, Renaud \& Ruiz, 2007) (Rouwenhorst et al., 2000b) (Baker \& Canessa, 2009). Since VSM has demonstrated promising results by its application in manufacturing industry, this research attempts to analysis how to apply VSM in warehousing context.

\section{Method}

Since a considerable VSM study foundation exists in the literature, the fundamentals of VSM are not explained in detail in this paper, but the interested readers are referred to related literature (Rother, Shook, Womack \& Jones, 1999).

Generally, Lean divides activities into two classes; those that add value and those that do not. Value added work can simply be defined as; "those activities that change the physical shape or assembly of a product". Due to the nature of warehousing, generally warehousing activities do not change the shape or assembly of items. Nevertheless, in warehouses, changes do occur with regards to the item unit type. Reviewing the current literature, warehousing processes can be divided into five abstract classes; receiving, storing, picking, sorting, and shipping(de Koster, Le-Duc, \& Roodbergen, 2007) (Abdoli \& Kara, 2016). An overview and a brief description of each process class and their objectives are given respectively in Figure 1 and Table 1. In Figure 1 and Table 1, SKU refers to Stock Keeping Unit.

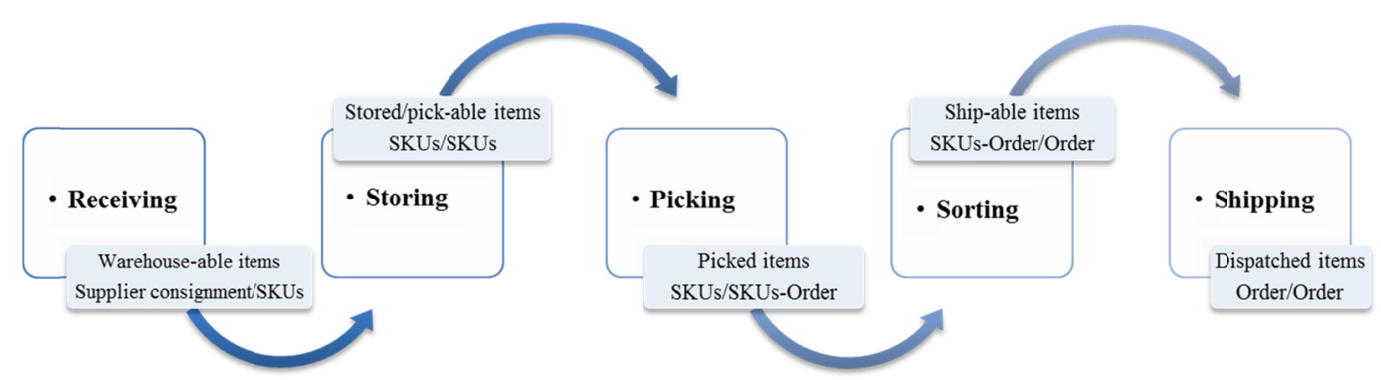

Figure 1.Warehousing processes objectives

Table 1. Warehousing Processes Description

\begin{tabular}{ll}
\hline Process name & Description \\
\hline Receiving & $\begin{array}{l}\text { Acquisition of inbound goods, and converting them into articles that are in the appropriate } \\
\text { condition for being stored or admitted in warehouse. The value created is transforming } \\
\text { inbounds items into 'warehouse-able' items. }\end{array}$ \\
Storing & $\begin{array}{l}\text { Allocates inbound items to warehouse storage, being available for such time as a customer } \\
\text { order triggers them for dispatching. availability }\end{array}$ \\
Order picking & $\begin{array}{l}\text { Retrieving customer requested items from storage } \\
\text { Qualifies the picked items to satisfy order requirements to be shipped. } \\
\text { Sorting }\end{array}$ \\
Shipping & $\begin{array}{l}\text { Enables dispatching of orders from the warehouse, such as loading the orders to truck (not } \\
\text { transshipment }\end{array}$ \\
\hline
\end{tabular}

To identify the value-adding activities within warehousing, this paper suggests reconsidering the role that warehouses play in the supply chain level at first. 
Then, it is recommended that the warehousing objectives should be defined with respect to the introduced enabler abstract processes. This is an important step for utilizing Lean concepts by application of VSM in warehousing. Considering a pool of possible processes and sub-processes, the warehousing function, $W_{f}$, can be represented as it shown in (1) and (2).

$$
\begin{gathered}
W_{f}=\left\{\left(\alpha_{i}, P_{i}\right)\right\} ; i \in\{1, \ldots, 5\} \\
\alpha_{i}=\left\{\begin{array}{c}
1 ; \text { if } P_{i} \text { is the enabler process for warehousing function } \\
0 ; \text { otherwise }
\end{array}\right. \\
P_{i}=\left\{\left(\beta_{k}, S P_{k}\right)\right\} ; k \in\{1, \ldots, K\} \\
\beta_{k}=\left\{\begin{array}{c}
1 ; \text { if sub }- \text { process } k \text { is needed in } P_{i} \\
0 ; \text { otherwise }
\end{array}\right.
\end{gathered}
$$

Where:

$\mathrm{K}$ : number of all sub-processes

$P_{i}$ : Process i

$S P_{k}:$ Sub-process k

For example; Warehouse A is assigned (from supply chain level) to change the status of items as follows; warehouse-able items, stored items, picked items, dispatched items, while warehouse B is assigned only the first and last of these activities. If $\alpha_{2}$ is assumed as the membership value of storing process, it will be 1 and 0 respectively for warehouse $\mathrm{A}$ and warehouse $\mathrm{B}$.

To distinguish value-adding from non-value adding activities within in each abstract process class, here, it is suggested to define those activities as non-value adding, if they perform after the item transits to the required status from that abstract process class. So, each sub-process of a process should be analyzed with respect to its abstract process and thus a value-adding activity in one process can be non-value-adding in another. Value-adding activities are generally recognizable, but sometimes non value-adding activities and waste are intertwined with value-added activities, making it difficult to clearly distinguish them from each other. Therefore some of these ambiguities will be discussed further.

Because of the long history of considering inventory as source of waste in Lean, it may seem bizarre not to consider warehouse inventory as waste. Basically, in finished goods warehouses, storing the items and carrying some inventory levels, let's term it dedicated capacity, is the main role of warehouse, such that inventory assists to absorb the risk of demand variation in the supply chain. Hence, it can't be so true to consider any level of inventory, even equal or less than dedicated capacity, as warehouse waste or inefficiency. Moreover, as explained, if warehouse does not have control over its inbound or outbound flows, changes in these flows may lead to inventory accumulation which exceeds the warehouse dedicated capacity. However, in the context of supply chain analysis, this exceeded inventory is waste and could happen due to inefficiency in so many forms such as poor supply planning. But, in the context of warehousing, the mentioned case of exceeded inventory from dedicated capacity is not due to warehouse inefficiency. In other word, the inventory accumulation, as waste in lean concept, can be in two forms; warehouse waste or supply chain waste. Warehouse waste is generated due to in-efficiency in warehousing operations whereas supply chain ones generated due to in-efficiency in supply chain planning level. However the supply chain waste could accumulate in warehouse, but these wastes should not be considered as warehouse waste. This research aims to apply Lean concepts by application of VSM in warehouse which its role is well defined in supply chain level. Hence, only that level of inventory, which occurs due to internal warehousing processes inefficiency, is suggested to be considered as warehouse waste.

As with manufacturing systems, most transportation between processes can be considered to be non-value-adding activity. In the current literature, picking and storing are considered to be the most time and cost consuming processes in warehousing, as a function of travel distance. Since, this paper suggests defining value-adding activities as those which directly change the item status, the travel of a picker from its dwell point to a storage module to pick items can be considered non-value-adding. Some examples of different picking/storing policies support this argument. Consider double command storing/picking process; the operator in first part of travel, stores the items in storage modules and in the way back to dwell point, picks the orders 
items from the storage modules. Double command process removes two empty travel of operator, back empty travel of operator to dwell point in storing process and empty travel of picker from dwell point to storage module. By operating on double-command mode, the items still achieve their intended status (being stored and being picked), through these two warehousing processes but with shorter transportation. This reasoning strongly supports the above mentioned novel argument regarding considering the item status as the criteria to distinguish the value-adding and non-value-adding activities in warehousing process.

\subsection{Analyzing Warehousing Processes Operational Units}

In general, the application of VSM seeks to measure an entire value stream with respect to the final process objective(s). In manufacturing systems, finished goods are the ultimate goal of production and their specifications are known in advance; thus inbound raw materials are easily translated into a number of possible finished goods. In warehousing, the ultimate objective is fulfilling customer orders, the specifications of which are not-known in advance. Nonetheless, in order to develop a holistic analysis for warehousing, defining an identical scale for all processes is critical which enables a consistent comparison. Therefore, this research sets out to analyze the existing operational unit(s) of warehousing processes and then examine the possible approaches for dealing with this issue for proper application of VSM in warehousing context, in section 2.2.

The transformation in item unit happens through warehousing processes, as demonstrated in Figure 2. Receiving and shipping are the warehouse interfaces with other network nodes, relative to suppliers and customers respectively. Hence, these processes deal with different units for the same item type; respectively supplier consignment units and customer order units.

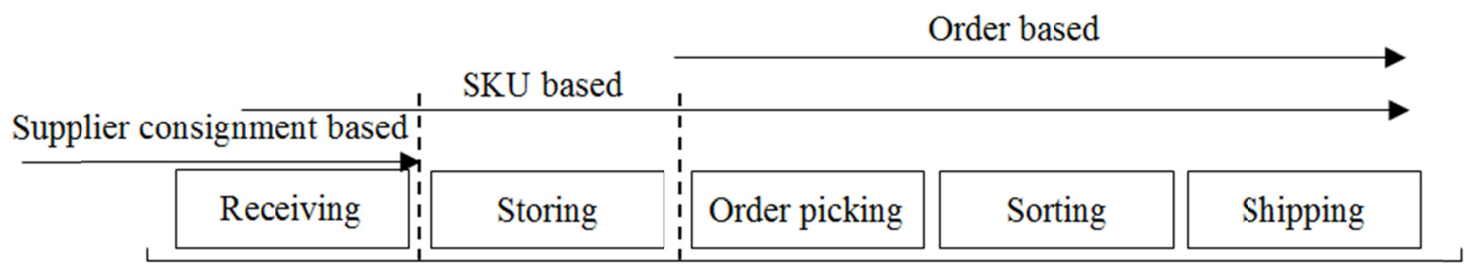

Figure 2. Different units in warehousing processes

Receiving process may include sub-processes, such as de-palletizing, which aim to change the supplier consignment units to SKUs. Once item units have been transferred to SKUs, the remaining sub-processes in receiving operate on an SKU base, as illustrated in Figure 2. As explained in table 1, storing process utilizes SKUs (warehouse-able items from receiving) without changing the item unit.

When the warehouse receives an order from a customer, depending on its operational policy, pick lists will be assigned to order pickers. Thus the picking process operates on SKUs but is also based on customer order definitions. Depending on the process design, the picking process can be carried out from either an SKU or an order basis. The sorting process qualifies the picked SKUs to meet the order specification. Hence it also operates on dual basis; SKU and order. Finally, the shipping process dispatches orders and this generally operates on an order basis but may also include some sub-processes that operate on SKU basis as well.

\subsection{Formulating Warehousing Process to Identical Operational Base}

As shown in Figure 2, SKU footprint can be observed in all warehousing processes. In addition, SKUs are utilized as an indicator for warehouse inventory levels as well as for both inbound and outbound activities. Moreover, since the SKU represents the most aggregated level of planning unit in warehousing context it is feasible to conduct process evaluation by using SKU as the scale unit. This research introduces some guidelines for the measurement of different types of warehousing processes with respect to SKUs.

At a very high level, processes can be categorized in to two categories, SKU-based and not SKU-based. Each category can also be subdivided, based on the process parameter type, into three sub-categories; fixed, constant, and variable. In the fixed sub-category, process parameters such as process time, are direct/determined functions of the number of operational units. For example, in the labelling process, the activity time or consumables are a direct function of the number of labelled SKUs. In the constant sub-category, the process parameters are independent from the number of operational units. Finally, in the variable sub-category, the process parameters may vary from one process to another. An example of a variable parameter might be travel distance (consequently process time) in the picking process, which may vary for different orders depending on required 
items in customer order.

As an initial step to formulate different process types on SKU base, warehousing processes should be decomposed into all possible sub-processes. Utilization of given representation in (1) and (2) can facilitate this step considerably.

The second step is to categorize all warehousing sub-processes into SKU-based/fixed, SKU-based/variable, SKU-based/ constant, not-SKU-based/ fixed, not SKU-based/variable, not SKU-based/constant.

For SKU-based processes, since they already operate based on SKU, there is no need to convert the process operational unit. In regards to not SKU-based processes, these may operate in three general conditions as follows;

1-Input SKU, output not-SKU: In this case, the number of inputs can be used to formulate process parameters as a function of SKU.

2-Input not SKU, output SKU: In this case, output number can be used to formulate process parameters as a function of SKU.

3-Input not SKU, output not-SKU: Here either 'expected' or 'Min-Max frontier' strategies can be utilized to estimate the average or a range for the number of SKUs in the process. The explanation of these strategies is given in section 2.2.1.

Up to this point all processes types could be converted to SKU base. It is worth noting that process parameters can vary from one operation to another. For example, the process parameters which are employed to measure typical process outcomes in VSMs are operation time, failure rate, resource and required consumables. Sometimes, the process parameter is a standalone KPI itself, such as process time. But, generally process KPIs are functions of process parameters. As shown in a generic representation in (4), $g$ is a function which maps the process parameter $P P$ to a KPI. In general, each specific KPI can be calculated based on a specific function and specific process parameter(s).

$$
\mathrm{KPI}=g(P P)
$$

Depending on the process parameter type (fixed, constant, variable), some further manipulation is required in order to formulating process parameters to SKU base, which is explained in section 2.2.1, 2.2.2 and 2.2.3.

\subsubsection{Processes with Variable Parameters}

For this process type, two methods are suggested; 'expected' and 'Min-Max frontier'. These approaches, as mentioned, can also be utilized when the number of operational units in a process is not determined.

Expected: Sometimes upon close examination of the historical data, a pattern can be observed and thus it may be possible to map the variable parameter to a probabilistic distribution function. The process parameter may then be represented as a function of some other variables as shown in (5).

PP: Process parameter defined as random variable

$\mathrm{PP} \sim \mathrm{D}$; PP has the probability distribution D

$\mathrm{P}(\mathrm{PP}=\mathrm{pp})$ : Probability that the $\mathrm{PP}$ has a particular value of pp.

$$
P P=f\left(x_{1}, . ., x_{2}\right)
$$

In the 'expected' approach, it is suggested to use an 'expected value' of the variable process parameter to estimate the related KPIs as shown in (6) to (10). PPS refers to the set of all possible values for $p p . P P^{\wedge}$ and $K P I^{\wedge}$ are respectively the estimated values for $P P$ and $K P I$.

$$
\begin{gathered}
E(P P)=\sum_{p p \in P P S}(p p \times P(p p)) ; P P S: \forall \text { acceptable values for } p p \\
E(P P)=\sum_{p p \epsilon P P S} f\left(x_{1}, \ldots, x_{2}\right) \times P(p p) \\
P P^{\wedge}=E(P P) \\
E(K P I)=E(g(P P))=g(E(P P)) \\
K P I^{\wedge}=g\left(P P^{\wedge}\right)
\end{gathered}
$$

It is worth noting that the benefits of this approach are not limited to the estimation of variable process 
parameters. This approach enables broad range of statistical analysis of KPIs. For example, if the modal value of a process parameter is more desirable than its expected value, KPIs can be easily interpreted with respect to the probability distribution function of the parameter.

Another advantage of this approach is that it enables one to analysis the occurrence chance of an acceptable KPI. For example, sometimes smaller values of PP guarantee meeting the desirable KPI. In this case, by utilizing the probability cumulative function $(\mathrm{F}(\mathrm{a}))$, the probability of meeting the desired KPI can be formulated as shown in (11).

$$
\begin{aligned}
\text { If } \mathrm{PP} \leq \mathrm{a} \rightarrow & \mathrm{KPI}=\mathrm{g}(\mathrm{pp} \leq \mathrm{a}) \leq \mathrm{b} \rightarrow \mathrm{KPI} \text { is acceptable, } \quad \mathrm{F}(\mathrm{a})=\mathrm{P}(\mathrm{PP} \leq \mathrm{a}) \\
& \mathrm{F}(\mathrm{a})=\mathrm{P}(\mathrm{KPI} \leq \mathrm{b}) \text {; the probability of meeting KPI }
\end{aligned}
$$

Thus, this approach enables one to capture the dynamic nature of a process, such that, scenarios may be developed and tested based upon different possible process outcomes. As mentioned, the order picking process is a good example of a process with variable process time and many researches have formulated the picking time as a function of travel distance (de Koster et al., 2007) By adjusting these generic formulas to warehouse specific conditions, the expected travel distance (accordingly process time) can be formulated. Generally, the picking time, $P T_{i}$, can be a function of many parameters, such as; $a_{l}$ : picking aisles length, $a_{w}$ : picking aisles width , $a_{h}$ : picking aisles height, $\mathrm{T}$ : number of aisles, dw: dwell point position, $\mathrm{D}$ : dock position, s: demand skewness, $o_{s}$ : order size, $o_{d v}$ : order diversity. Hence, the picking time and its estimated value can be presented as follows:

$$
P T_{i}=f\left(a_{l}, a_{w}, a_{h}, T, d w, D, s, o_{s}, o_{d}\right), \quad P T_{i} \approx E\left(P T_{i}\right)
$$

The abovementioned parameters for the picking process can be divided into two general categories; deterministic and non-deterministic. Some parameters are fixed, such as the number of aisles whereas some parameters, such as order diversity or order size, may vary from one order to another. These non-deterministic parameters introduce variability to the process time. As mentioned, observing historical data can reveal order profile patterns, which can then be mapped to a probability distribution function. Hence, the chance of receiving different order sizes with different diversity can be formulated. As shown in (12), the expected value is formulated based on two elements. First element is the probability of receiving orders with specific size and diversity as a function of non-deterministic parameters. The second element is the accordance picking time with respect to the received specific order and deterministic parameters. The order diversity can range from one to maximum order size. The former represents a single order line, whilst the later indicates one single item per SKU in the order.

$$
E\left(P T_{i}\right)=\sum_{s=1}^{S} \sum_{D V=1}^{D V=S} P\left(o_{s}, o_{d v}\right) \times f\left(a_{l}, a_{w}, a_{h}, T, d w, D, s, o_{s}, o_{d v}\right)
$$

Min-Max frontier: If the explained 'expected' approach is not applicable, or for ease of calculation, Min-Max frontier approach is suggested. In this approach the possible minimum and maximum values of variable process parameters should be estimated. These thresholds constitute a feasible range for the variable parameters and accordingly for the process KPIs, as represented in a generic form in (13) and (14).

$$
\begin{gathered}
P P_{\min }<P P<P P_{\max } \\
K P I_{\text {min }}<K P I<K P I_{\text {max }}
\end{gathered}
$$

Recalling the picking process, considering the furthest and closest storage modules, the longest and shortest travel distances (consequently process times), can be obtained. Although this approach determines some thresholds and not one specific value for the variable parameter, it nevertheless provides an acceptable insight from variable process parameter to interpret the related KPI.

\subsubsection{Processes with Fixed Parameters}

Since in this process type, process parameters are a direct function of the number of operational units, $x$, it is quite straight forward to formulate KPIs when a process is aligned to a SKU base. The generic form of this approach is shown in (15) and (16).

$$
\begin{gathered}
P P=h(x) \\
K P I=g(h(x))
\end{gathered}
$$

\subsubsection{Processes with Constant Parameters}

If the number of operational units is constant, $x_{\text {constant }}$, KPIs can be calculated on a SKU base by using the constant process parameter; as shown in (17) and (18). 


$$
\begin{gathered}
P P=\mu \times x_{\text {constant }} ; \mu: \text { constant coefficient } \\
K P I=g\left(\mu \times x_{\text {constant }}\right)
\end{gathered}
$$

If the number of operational units is variable, the 'expected' or 'min-max frontier' approach can be applied to estimate the number of operational units and from that, the relevant KPI can be calculated. In case of variable number of operational units, the variable parameter is $x$.

The generic representation of applying 'Expected' method to estimate KPI, when the operational unit is variable, is shown in (19)-(22). Consider the case that fork lifts carry different SKU numbers from docks to a stacking area with constant carrying time. If historical data reveals that carrying SKUs follows a uniform distribution with definable minimum and maximum SKUs, using the distribution parameters the expected number of carrying SKUs can be considered for estimating process parameters/KPIs.

$$
\begin{gathered}
\mathrm{PP} \approx \mathrm{E}(\mathrm{h}(\mathrm{x})) \\
\mathrm{PP} \approx \mathrm{h}(\mathrm{E}(\mathrm{x})) \\
\mathrm{PP}^{\wedge} \approx \mathrm{h}\left(\mathrm{x}^{\wedge}\right) \\
\mathrm{KPI}^{\wedge}=\mathrm{g}\left(\mathrm{h}\left(\mathrm{x}^{\wedge}\right)\right)
\end{gathered}
$$

As mentioned, 'Min-Max frontier' can also be utilized to estimate the variable number of operational unit, $x$. In this approach the maximum and minimum number of operational inputs is considered, which provides a range for process parameters and accordingly KPIs as shown in (23)-(25).

$$
\begin{gathered}
x_{\text {min }}<x<x_{\text {max }} \\
P P=\left\{h(x) \mid \forall x \in\left\{x_{\text {min }}, x_{\text {max }}\right\}\right\} \rightarrow\left\{P P_{\text {min }}, P P_{\text {max }}\right\} \\
K P I=\left\{g(P P) \mid \forall P P \in\left\{P P_{\text {min }}, P P_{\text {max }}\right\}\right\} \rightarrow\left\{K P I_{\text {min }}, K P I_{\text {max }}\right\}
\end{gathered}
$$

If the 'min-max frontier' approach is applied to more than one process, the possible combination of min and max values for all processes should be taken to account and the corresponding global min and max should be chosen for the KPI. For example, consider that 'min-max frontier' approach is applied to estimate process time of storing and picking process, $P_{2}$ and $P_{3}$. The storing and picking process time, $P T_{2}$ and $P T_{3}$, can sit within the ranges given below, by considering the effective parameters; such as furthest and closest storing/picking modules, maximum and minimum order size and diversity.

$4 \mathrm{~min}<P T_{2}<12 \mathrm{~min}, \quad 5 \mathrm{~min}<P T_{3}<12 \mathrm{~min}$

Hence, by application of the 'min-max' strategy on these two processes, their total process time, $P T$, results in the below range.

$P T=\{9,16,17,24\} \rightarrow 9 \min <P T<24 \mathrm{~min}$

Utilizing explained methods in 2.2, all warehousing processes can be formulated in such a way that all types of processes can be measured with an identical scale unit, the SKU.

\subsection{Formulating Order-Based KPIs}

Generally, it is more preferable to measure process KPIs with respect to the eventual objectives of a process chain. In the application of VSM to manufacturing systems, everything should be measured with respect to finished goods, for which specifications are predetermined. In the warehousing context customer order fulfilment is the main objective which the orders specifications are not known in advance and can vary from one order to another. This ambiguity was the main reason that the SKU was chosen as the common unit for process evaluation in section 2.2.1. Nevertheless, it is still preferable to interpret warehousing KPIs with respect to customer order profile. Hence, SKU-based KPIs must be transformed into order-based KPIs. It is again suggested to utilize either the expected or min-max approach for order profile estimation. Estimation of order profile is different to demand forecasting. In demand forecasting the total number of customer orders over a time period are forecasted. Whereas, order profiling seeks to find patterns within orders, such as order size or item diversity, respectively; $s, d v$.

If 'Expected' approach is utilized, probability distribution functions, such as $P_{1}, P_{2}$, can be assigned to variable parameters of orders, such as order size and diversity, $s, d v$. By estimating these parameters, as shown in (26), 
the process KPIs can be converted from SKU-based to order-based, $K P I_{o b}$, as shown in the generic formulations in (27)-(30).

$$
\begin{gathered}
s^{\wedge}=E\left(P_{1}\right), d v^{\wedge}=E\left(P_{2}\right) \\
K P I_{o b}=g(P P \mid S, d v) \\
K P I_{o b}=g\left(P P \mid\left(P_{1}, P_{2}\right)\right) \\
K P I_{o b} \wedge \approx g\left(P P \mid E\left(P_{1}\right), E\left(P_{2}\right)\right) \\
K P I_{o b} \wedge \approx g\left(P P \mid s^{\wedge}, d v^{\wedge}\right)
\end{gathered}
$$

In a simple example, if the process time for single SKU was calculated 5 minutes and the expected order size was 20 (assuming single order line); then the expected process time for order can be approximately 100 minutes.

As mentioned, for simplicity, 'Min-Max' approach can also be utilized to convert SKU based KPIs to order based KPIs. In this case, the described logic regarding the Min-Max strategy in 2.2.1 applies here too. Min-Max' approach provides a range for order based KPIs as shown in (31)-(34).

$$
\begin{gathered}
s_{\text {min }}<s<s_{\text {max }} \\
d v_{\text {min }}<d v<d v_{\text {max }} \\
P P_{o b}=\left\{P P \mid s_{\text {min }}<s<s_{\text {max }}, d v_{\text {min }}<d v<d v_{\text {max }}\right\} \rightarrow\left\{P P_{\text {min },} P P_{\text {max }}\right\} \\
K P I_{o b}=\left\{g(p p) \mid \forall p p \in\left\{P P_{\text {min }}, P P_{\text {max }}\right\}\right\} \rightarrow\left\{K P I_{\text {min }}, K P I_{\text {max }}\right\}
\end{gathered}
$$

In general, if the 'expected' strategy is applied to estimate a KPI, one should be more conservative about the interpretation of the KPI since there is always the possibility of error due to the inherent uncertainty in estimated parameters. This issue may be resolved by defining an acceptable significance level and confidence interval for the estimated parameters. Sensitivity analysis can also assist in analyzing the effects of parameter variation on the whole process chain.

\subsection{Product Families Creation}

Generally VSM is applied to product families, rather than to individual products(Nielsen, 2008). Therefore, creating product families in the warehousing context is discussed in this section. In manufacturing context, the product type specification is usually the source of product family differentiation. However in warehousing there are multiple sources of differentiation; customer's orders, suppliers or item specifications. Each of these may imply some effects in different stages of warehousing abstract function, as illustrated in Figure 3. It is worth to mention that the given illustration in Figure 3 is based on a general warehousing process configuration and some exceptions may not exactly follow this representation.

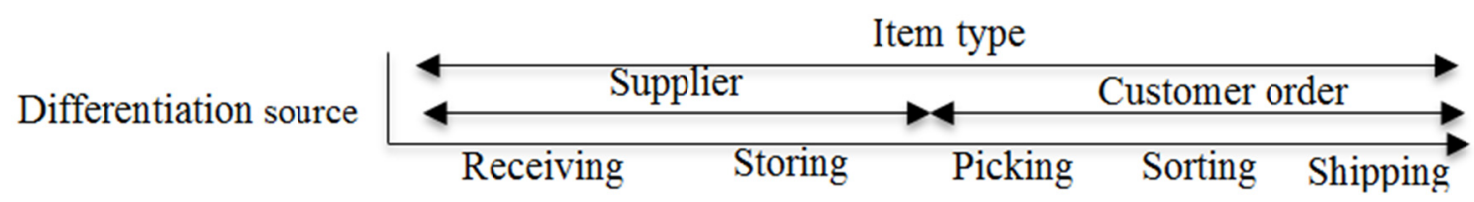

Figure 3. Impact range of differentiation sources in warehousing

As shown in Figure 3, three main sources; supplier, SKU and customer order can cause differentiation in SKUs required processes in a warehouse. SKU differentiation source has the highest impact range. Because, each specific item may vary in required operations in each of the five mentioned abstract process classes, which affects the whole life cycle of an item in its warehousing journey.

Different suppliers can affect the required processes for a single SKU up to picking process, in order to make warehouse-able and stored items from supplier consignment. In other word, the impact range of supplier differentiation source is upstream processes of order picking. For example, consider a warehouse that receives SKU001 from two suppliers. Supplier A provides this SKU type in cartons whilst B provides the product on 
pallets. Hence the receiving process may change depending on the supplier; whether the inbound product requires de-palletizing sub-process or not.

As soon as the items are stored, their status will change to SKU, and generally, any other process afterward will be applied because of customer order. Any stored SKU that meets the customer order specification can be picked and any history of upstream processes is not considered. In other word, the impact range of customer order differentiation source is downstream processes from order picking. As an example, in dispatching the mentioned SKU001, one customer needs standard packaging whilst the other requires special packaging. Here the packing process will vary for the same SKU. In this simple case for one specific SKU, four different process configurations exist which should be added to the variation in process configuration due to different SKU types. Since warehouses generally deal with numerous item types, suppliers and customers, it would be much easier to follow the causes of differentiation in order to develop product families. The suggested approach can be demonstrated hierarchically, as shown in Figure 4. The arrows indicate the sources of differentiation.

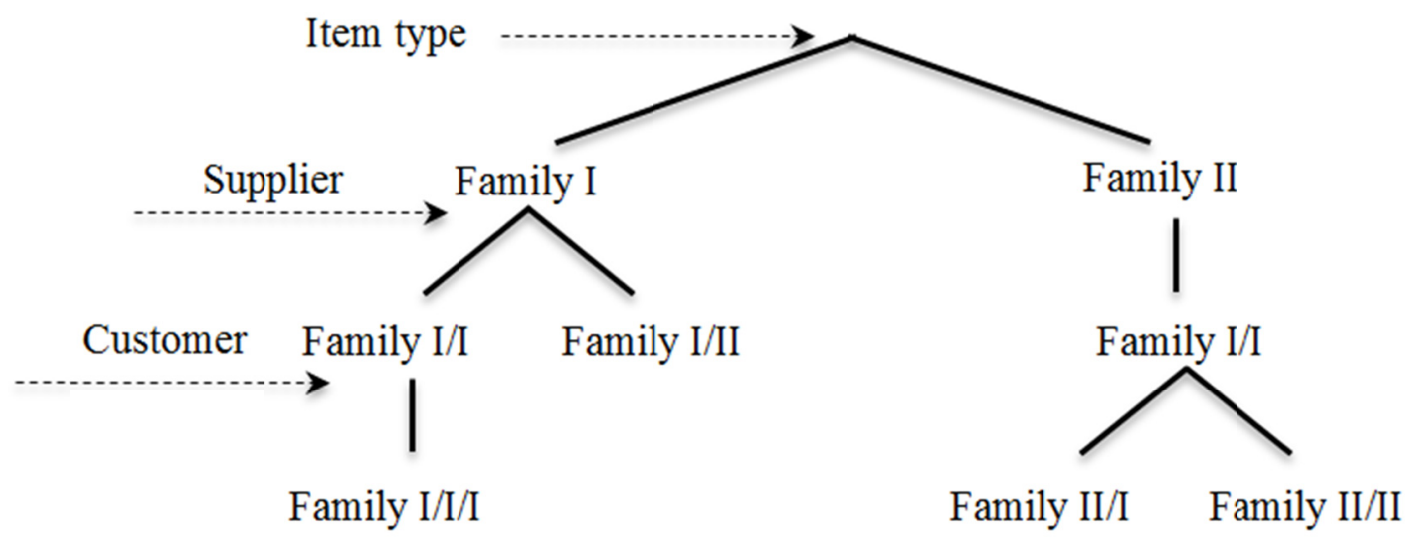

Figure 4. Schematic view of making item family for warehousing items

\section{Case Study}

The studied warehouse is a distribution center for an international healthcare company. It receives $70 \%$ of its SKUs from a domestic factory replenishment center and these constitute the fast moving items of the distribution center. The items received from the replenishment center can be grouped in one family, since they have the same supplier and share same processes and resources and these have been chosen for this study. This warehouse runs all five main warehousing processes and so it is a good candidate for a comprehensive study. In this case, item-unit changes from supplier consignment to pallet, from pallet to SKU and from SKU to customer order. The receiving process includes two sub-processes; unloading and stacking; $P_{11}, P_{12}$. Storing, picking, sorting and shipping are respectively shown $P_{2}, P_{3}, P_{4}$ and $P_{5}$. Using (1), the warehouse processes can be formulated as follows:

$$
W_{f}=\left\{\left(\left(1, P_{11}\right),\left(1, P_{12}\right)\right),\left(1, P_{2}\right),\left(1, P_{3}\right),\left(1, P_{4}\right),\left(1, P_{5}\right)\right\}
$$

$P_{1}$ is an automatic sub-process, which receives 5 loads each weekday morning, each containing 33 pallets of 10 SKUs and is followed by stacking process. Considering the given objectives for receiving processes in Table.1, both the receiving sub-processes are considered as value adding, since they convert supplier consignments to warehouse-able items. For the sake of brevity, it is sufficient to provide some example calculations with the rest are shown as results in Figure.5. Since the SKU quantity is constant in each load, the receiving process can easily be formulated to a SKU basis as follows;

$P_{11}$-time for truck load=30 minutes, $P_{11}$-time per $\mathrm{SKU}=30 / 33 \times 10=0.091$ minute.

In the storing process, the forklift driver first drives to the stacking area, then picks pallets, drives to the storing area, puts the pallets in the racks and then comes back. As explained earlier, the driving component of this process can be considered as non-value-added but necessary activities, whilst the positioning of items in racks is considered as the main storing process. The transportation and $P_{2}$ have variable run time depending on item's position in the storage area, aisle position, and shelf height. Observing historical data, a Pareto-distribution with 
proper shape and scale parameters, can be a good estimator for the storing process time, $P T_{2}$.

$$
\begin{gathered}
P T_{2} \sim \operatorname{Pr}(\mathrm{t}) \rightarrow P T_{2} \wedge=E(\operatorname{Pr}(\mathrm{t})) \\
P T_{2} \wedge=3 \text { minutes/pallet } \\
P T_{2-S K U \text { based }} \wedge=3 / 10=0.3 \text { minutes }
\end{gathered}
$$

The warehouse has a static time window in which to receive orders and after that $P_{3}$ starts. Pickers pick required items and sort them in sorting matrix in preparation for shipment. Pareto-distribution with proper shape and scale parameters can also be a good estimator for picking process, by considering the storing policy, storage area configuration and other related parameters.

$$
\begin{gathered}
P T_{3} \sim \operatorname{Pr}(\mathrm{t}) \\
P T_{3-S K U \text { based }^{\wedge}} \wedge=0.5 \text { minutes }
\end{gathered}
$$

As demonstrated in Figure 5, instead of showing a single value for the estimated parameters, these are represented as distribution functions. For clarity, the adjusted Pareto diagrams are rotated 90 degrees and the dashed-lines show the expected values of each distribution. One may consider each value in the distribution function, for KPI estimation, by considering its corresponding probability.

Analyzing the order profile, the order size varies from 3 to 11 SKU per order with average of 9, which larger orders are more common. Since the sorting area is small, hence arranging larger orders is not measurably longer than smaller orders; sorting process is almost identical free from order size. The sorting process can be converted to SKU base by considering its expected value of operational units.

$$
\begin{gathered}
\mathrm{PT}_{4}=5 \text { minutes } \\
\mathrm{PT}_{4-\text { SKU based }} \wedge\left(\mathrm{PT}_{4} \mid \text { order size }=9\right) \approx 0.56 \text { minutes }
\end{gathered}
$$

For the purpose of demonstration in this case study, the typical metrics in the VSM are primarily examined, such as process time; however other KPIs can also be easily formulated. The current state map of the described warehouse, with restructured SKU-based processes, is illustrated in Figure 5. In order to demonstrate order-based KPIs, the process parameters are divided to 9 (average order size), shown as the bottom line in Figure 5.

\subsection{Discussion}

As discussed earlier, the duration of stay of a SKU in the warehouse is not an indicator of warehouse inefficiency. In this case study, from receiving to storing, all processes operate on push mode and only customer orders send a pull signal to trigger picking process. This makes picking as the decoupling point, and the pacemaker of the warehousing function. Hence, as illustrated in Figure.5, the stored items are shown in supermarket, instead of wrongly showing them as work in progress (WIP). The lead time in the supermarket indicates the time interval from receiving an order to picking it from the racks. In other words, lead times before the decoupling point indicates the SKU's waiting time to progress to successive process, whereas the cumulative values of lead times after decoupling point represent the order lead-time.

The total process time of each single SKU is expected to be 1.906 minutes. However, depending on non-deterministic process parameters, this value can vary. The variation of storing and picking process time and their transportation sub processes have led to a non-smooth process chain as captured and shown in the dynamic VSM representation in Figure.5. This variation sometimes results in either idle time or resource bottleneck. Upon closer inspection, sorting and picking tend to be the most time consuming processes, which is reasonable since the studied warehouse is a customer-facing warehouse. Moreover, since picking is the pacemaker it is a good candidate for improvement. Combining the storing and picking processes as one process may help to absorb some variation from both processes and providing the warehouse operates with greater stability. This approach promises to increase process efficiency as discussed in the literature and to warehouse managers in the exemplar organization concur that application of double command storing-picking process would improve efficiency and also create smoother flow. Demonstrating such a future state map is not in the scope of this paper but would follow the same procedures set out in this paper. 


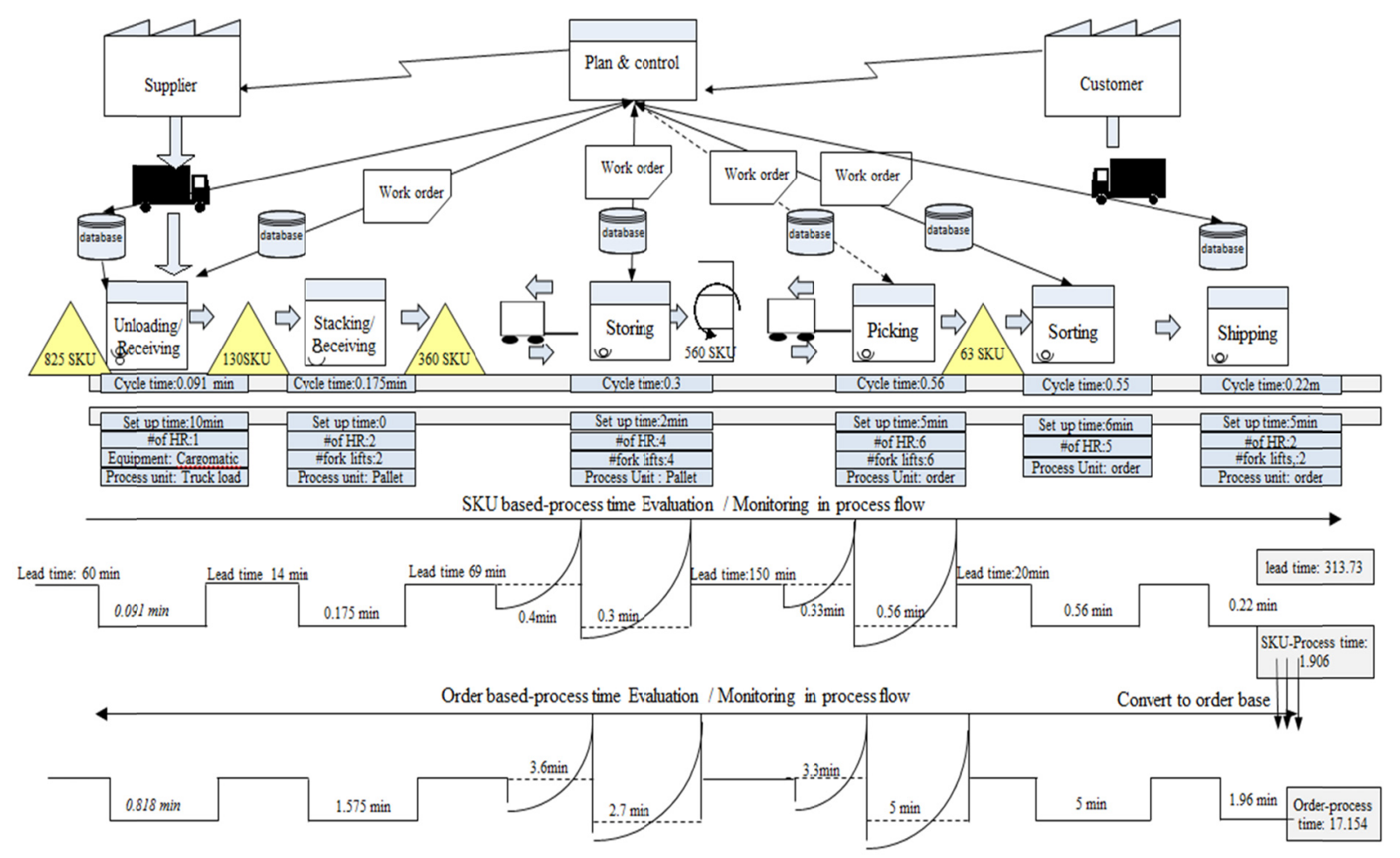

Figure 5. Dynamic VSM applied in a real case study

\section{Conclusion}

The application of VSM in a warehousing context was studied in this paper. As one of the main contributions of this paper, a novel abstract classification of warehousing processes was given, based on process output status. This abstract classification enables the description of warehousing functions based on their processes. This approach simplifies the distinction of value-adding, non-value-adding activities and waste, which are intertwined in a warehousing context. In addition, this representation of item unit transformation in warehousing processes enables the development of a common scale and unit for process chain evaluation. 'Min-Max frontier' and 'expected' methods were proposed to deal with the non-deterministic or uncertainty in warehousing processes. These methods represent non-deterministic values (such as random process parameters) with a probabilistic distribution function or a range, instead of demonstrating one single value in VSM. This novel approach helps to overcome the embodied uncertainty in an entire value stream including variation in supply (such as consignment size), variation in process parameters (such as travel distance in picking process) and customer order (order size and type). It is worth mentioning that the suggested approach in this paper can be undertaken to apply VSM in any process chain containing variable process parameters and is not limited to warehousing context. The introduced dynamic VSM, with embodied statistical and mathematical analysis, can reflect the dynamic nature of processes and also give a comprehensive and understandable insight of a process chain KPIs. All of these results can greatly support the decision making process regarding process design, configuration and improvement. At the end, research regarding the application of the proposed methodology in systems which run as process chain in other domains can be a potential future research. Formalization of the introduced concepts and methods for the general application of the proposed methodology can be studied as well.

\section{References}

Abdoli, S., \& Kara, S. (2016). Designing Warehouse Logical Architecture by Applying Object Oriented Model Based System Engineering. Procedia CIRP, 50, 713-718. http://dx.doi.org/10.1016/j.procir.2016.04.108

Baker, P., \& Canessa, M. (2009). Warehouse design: A structured approach. European Journal of Operational Research, 193(2), 425-436. http://dx.doi.org/10.1016/j.ejor.2007.11.045

Ben, N. J., Naim, M. M., \& Berry, D. (1999). Leagility: Integrating the lean and agile manufacturing paradigms in the total supply chain. International Journal of Production Economics, 62(1-2), 107-118. http://dx.doi.org/10.1016/S0925-5273(98)00223-0 
Berg, J. P. V. D., \& Zijm, W. H. M. (1999). Models for warehouse management: Classification and examples. International Journal of Production Economics, 59(1-3), 519-528. http://dx.doi.org/10.1016/S0925-5273(98)00114-5

Bozer, Y. A. (2012). Developing and Adapting Lean Tools/Techniques to Build New Curriculum/Training Program in Warehousing and Logistics. University of Michigan Department of Industrial and Operations Engineering.

Detty, R. B., \& Yingling, J. C. (2000). Quantifying benefits of conversion to lean manufacturing with discrete event simulation: A case study. International Journal of Production Research, 38(2), 429-445. http://dx.doi.org/10.1080/002075400189509

Dotoli, M., Epicoco, N., Falagario, M., Costantino, N., \& Turchiano, B. (2015). An integrated approach for warehouse analysis and optimization: A case study. Computers in Industry, 70, 56-69. http://dx.doi.org/10.1016/j.compind.2014.12.004

Frank, C., \& Garcia, P. E. (2013). Applying Lean Concepts in a Warehouse Operation. Advent Design Corporation.Bristol, PA, USA.

Gagliardi, J. P., Renaud, J., \& Ruiz, A. (2007). A simulation model to improve warehouse operations. Proceedings of the 2007 Winter Simulation Conference, 1-5, 1991-1997.

Gray, A. E., Karmarkar, U. S., \& Seidmann, A. (1992). Design and operation of an order-consolidation warehouse: Models and application. European Journal of Operational Research, 58(1), 14-36. http://dx.doi.org/10.1016/0377-2217(92)90232-X

Gu, J. X., Goetschalckx, M., \& McGinnis, L. F. (2010). Research on warehouse design and performance evaluation: A comprehensive review. European Journal of Operational Research, 203(3), 539-549. http://dx.doi.org/10.1016/j.ejor.2009.07.031

Gu, J., Goetschalckx, M., \& McGinnis, L. F. (2007). Research on warehouse operation: A comprehensive review. European Journal of Operational Research, 177(1), 1-21. http://dx.doi.org/10.1016/j.ejor.2006.02.025

Henrik, B., Mats, I. J., \& Lars, M. (1994). A Methodology for Evaluation of Order Picking Systems as a Base for System Design and Managerial Decisions. International Journal of Operations \& Production Management, 14(3), 126-139. http://dx.doi.org/10.1108/01443579410058595

Hofer, C., Eroglu, C., \& Rossiter, H. A. (2012). The effect of lean production on financial performance: The mediating role of inventory leanness. International Journal of Production Economics, 138(2), 242-253. http://dx.doi.org/10.1016/j.ijpe.2012.03.025

Jones, D., Hines, P., \& Rich, N. (1997). Lean logistics. International Journal of Physical Distribution \& Logistics Management, 27(3/4), 153-173. http://dx.doi.org/10.1108/09600039710170557

Koster, R., Le-Duc, T., \& Roodbergen, K. J. (2007). Design and control of warehouse order picking: A literature review. European Journal of Operational Research, 182(2), 481-501. http://dx.doi.org/10.1016/j.ejor.2006.07.009

Liker, J. K., \& Convis, G. L. (2011). The Toyota way to lean leadership: achieving and sustaining excellence through leadership development. New York: McGraw-Hill.

Mustafa, M. S. (2015). A Theoretical Model of Lean warehousing (Doctoral dissertation). Politecnico di Torino. http://dx.doi.org/10.6092/polito/porto/2588573

Myerson, P. (2012). Lean Supply Chain and Logistics Management: McGraw-Hill Education.

Nielsen, A. (2008). Getting Started with Value Stream Mapping: Gardiner Nielsen Associates Inc.

Pavnaskar, S. J., Gershenson, J. K., \& Jambekar, A. B. (2003). Classification scheme for lean manufacturing tools. International Journal of Production Research, 41(13), 3075-3090. http://dx.doi.org/10.1080/0020754021000049817

Rother, M., Shook, J., Womack, J., \& Jones, D. (1999). Learning to See: Value Stream Mapping to Add Value and Eliminate MUDA (e. E. I. S. edition Ed.): Lean Enterprise Institute; Spi edition.

Rouwenhorst, B., Reuter, B., Stockrahm, V., Houtum, G. J. V., Mantel, R. J., \& Zijm, W. H. M. (2000). Warehouse design and control: Framework and literature review. European Journal of Operational Research, 122(3), 515-533. http://dx.doi.org/10.1016/S0377-2217(99)00020-X

Rouwenhorst, B., Reuter, B., Stockrahm, V., Houtum, G. J. V., Mantel, R. J., \& Zijm, W. H. M. (2000). 
Warehouse design and control: Framework and literature review. European Journal of Operational Research, 122(3), 515-533. http://dx.doi.org/10.1016/S0377-2217(99)00020-X

Womack, J. P., \& Jones, D. T. (2003). Lean Thinking: Banish Waste and Create Wealth in Your Corporation, Revised and Updated (2nd edition ed.): Productivity Press.

\section{Copyrights}

Copyright for this article is retained by the author(s), with first publication rights granted to the journal.

This is an open-access article distributed under the terms and conditions of the Creative Commons Attribution license (http://creativecommons.org/licenses/by/4.0/). 